\title{
A SUDDEN UNEXPECTED DEATH OF A CHILD A RARE CAUSE
}

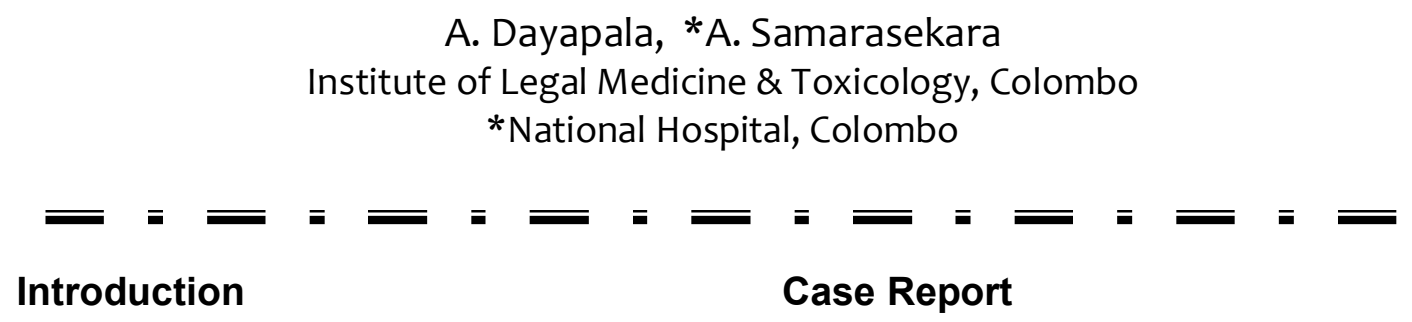

Sudden unexpected natural deaths in adults are usually attributed to cardiac causes and Ischemic Heart Disease is the leading cause in the older age group. In children, the scenario is different and most cardiac deaths are due to congenital cardiac abnormalities which occur approximately $1 \%$ of live births.(1) Therefore it is understandable the rarity of other fatal conditions which include cardiomyopathies, valvular heart disease and electrical abnormalities of conduction system resulting sudden cardiac deaths.

Diverticular Disease of Heart or Congenital Cardiac Aneurysms have been considered to be a rare entity causing sudden cardiac deaths.(2) But a recent research has shown that its occurrence can be higher and can be demonstrated by cardiac imaging techniques.(3)

The failure to appreciate the true occurrence is thought to be due to the silent nature of the entity. But it can have fatal consequences (4)(5) Then such cases invariably end up in the Forensic Practitionerôs hand. That is the very reason should the Forensic Practitioner be aware of its existence. It is also important for the forensic pactitioner to distinguish congenital aneurysms from aneurysms caused by other pathologies such as ischemia, trauma, inflammation and rubella though it will be difficult at times.(2) (6) (7)
The deceased was a six-year-old girl and the $3^{\text {rd }}$ of the family of three children. She had been a healthy child without any known disease or complaints except a heavy weight falling on the body exactly a month ago and an attack of chicken pox several months ago. She had been hospitalized following the accident when a barrier at road side has collapsed on her while passing it. At that time her main symptoms were dyspnea for about 10 minutes and loss of consciousness. After admission her vital parameters were normal. She has undergone X-ray of chest which had appeared unremarkable. She had not been subjected to ECG examination and had been discharged on the $2^{\text {nd }}$ day on analgesics. Thereafter she had been symptom free for one month.

On the fateful day around 7.30am she, has had the usual cup of milk tea prepared by her mother. Little later, she has tried to reach for a bun on the table and suddenly collapsed supine on cement floor without striking against anything. Then the child had developed a fitting attack and soon became motionless. She was rushed to a leading childrenôs hospital that was reachable in 15 minutes. The doctor of the Out Patient Department initiated cardiopulmonary resuscitation with cardiac massage and intubation but pronounced her dead on admission in a while. As the cause for this sudden death was not clear, the inquest was held and the body was sent for postmortem examination in the same evening. 
On external examination, the body was cold and in full rigor mortis. The deceased was fairly nourished and $121 \mathrm{~cm}$ in height. Little amount of whitish froth was noted at nostrils. There were no injuries except $1 \mathrm{~cm}$ laceration in the inner aspect of lower lip with intact frenulum. The body was free of old scars. The scalp, skull and brain were unremarkable and neck dissection did not revealed any abnormality or injuries. There was no evidence of hemopneumothorax or adhesions in chest cavity or pericardium. The pericardial sac was found distended with blood. On opening of pericardial cavity, $150 \mathrm{ml}$ of clotted and liquid blood could be evacuated. There was a vertical rupture approximately $7 \mathrm{~mm}$ with necrotic margins found left to the anterior descending branch of left coronary artery in the upper part of the anterior wall of the left ventricle (Fig 1). Further dissection of the left ventricle revealed that the rupture was communicating with a cavity approximately measuring $1.2 \mathrm{~cm}$ $\mathrm{x} 1 \mathrm{~cm} \times 1 \mathrm{~cm}$ in the myocardium which in turn communicating with the left ventricular cavity with a narrow ostium among trabeculae.(Fig 2) (Fig 3). There was another similar unruptured cavity with blood clot found close to the apex of the heart in the anterior wall of left ventricle (Fig3). There were no other abnormalities found in great vessels, coronary arteries, cardiac valves or chambers. The stomach contained $100 \mathrm{ml}$ of creamy white liquid without remarkable smell. The rest of the organs were unremarkable.

The histology of the lesions showed extensive mature fibrosis with out mucosal lining or inflammatory changes. The fibrous tissue was only seen in relation to the lesions.(Fig 4) Ruptured margin had necrotic tissues. Clotted blood with out organization was seen in the unruptured lesion. (Fig 4) Histology of the rest of the heart and the other organs were unremarkable.

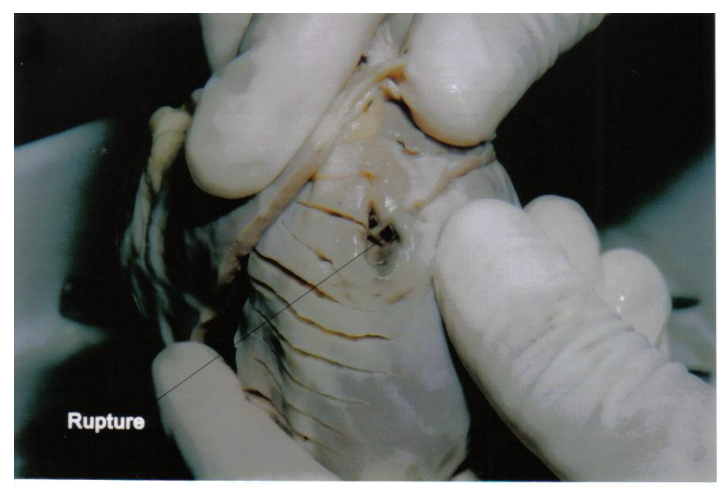

Figure - 1

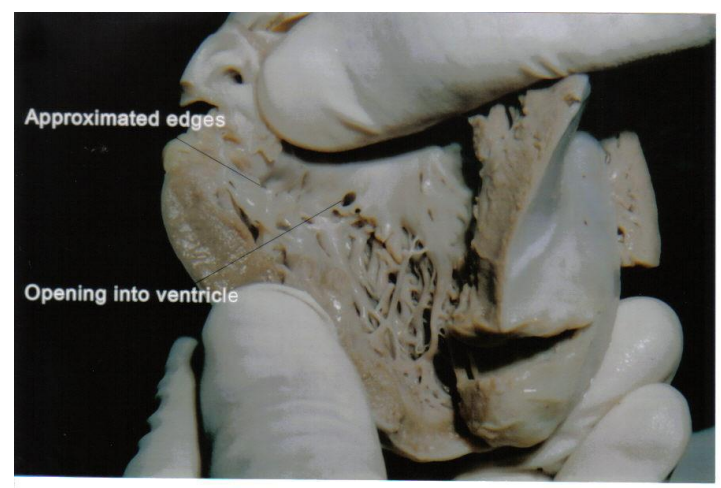

Figure - 2
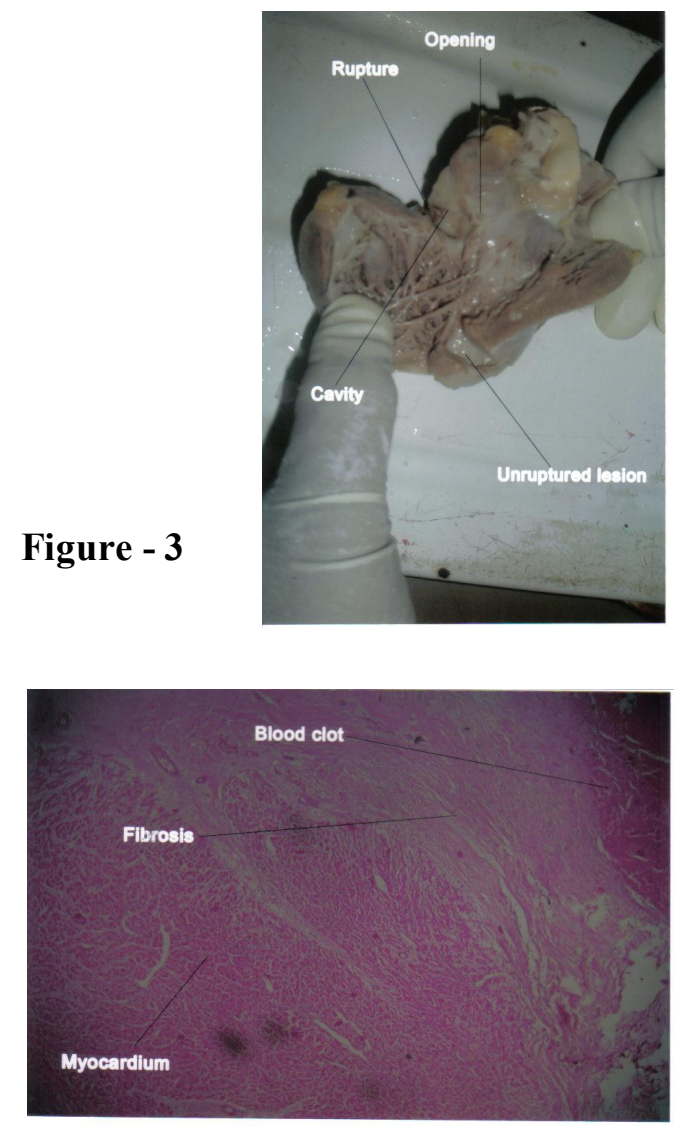

Figure - 4 


\section{Discussion}

The main non traumatic cause of hemopericardium in adult population is myomalasia cordis following infarction.(8) But spontaneous hemopericardium can be caused by ruptured lesions other than infarctions and those lesions includes Hydatid cysts, Foregut cysts(9) and Diverticular Disease or Congenital Aneurysms of the heart.(2)(3)

Out of these, hydatid cysts are the commonest.(9)(10) They can cause cardiac tamponade if ruptured.(10) Those cysts can be shelled out easily from myocardium.(10) Appearance and histology of the case under discussion is unlikely to be a case of hydatid cysts.

Foregut cysts are developmental abnormalities arising from primitive foregut. They are divided into bronchogenic cysts or enterogenic cysts according to their origin. They usually contained sebaceous or necrotic materials. The surrounding area can have fibrosis. They have mucosa akin to respiratory or gut mucosa.(11 )(12)

Cardiac diverticulum is a congenital abnormality of unkoun eatiology. (2) They can be fibrous or muscular. The muscular varity is usually associated with other midline congenitla abnornmalities.(2) They have to be differenciated from poorly compacted ventricular myocardium.(3) The communication of a muscular diverticulum with ventricle is narrow. They can remain silent or can cause complications such as arrhythmia , cardiac rupture or heart failure.(2) The fibrous varity is usually occurening as a sole pathology and occurs at the apex or base of the heart. They usually have a wider neck. (2)(6)They have to be differenciated from cardiac aneurysms of secondary origin such as trauma, ischemia, rubella and inflammatory causes (2) (6)

This case had extensive mature fibrosis around the lesions. There was no histologically demonstatable lining in the cavity. They had narrow communication with ventricular cavity. This is in contrast to the fact that fibrous diverticulae usually have a wide communication.(2) Their appearance and histology are in favor of cadiac diverticular or cardiac aneurysms. It is said that these two terms are used interchangeably. But it is more scientific to use the term ñdivericulumò when the communication with the ventricular cavity is narrow.(6) Other congenital abnormalities are common with muscular diverticular disease of the heart.(6) Occurrence of fibrous diverticula as the sole lesion causing fatal hemopericardium has been reported.(5)But before coming to a diagnosis of congenital fibrous diverticular disease or aneurysm, it is necessary to exclude causes which can result in similar lesions. Those causes include trauma, mycotic lesions, syphilis, rubella myocarditis and congenital abnormalities in coronaries and major blood vessels causing myocardial ischemia.(2) (6). In the case under discussion there were no pathologies which could have caused secondary aneurysms detected. History of blunt trauma to chest a month ago raise the possibility of cardiac aneurysm following myocardial damage (6)(7). But had she have extensive damage to myocardium at that time, it is unlikely for her to be free of symptoms and sign on admission after trauma and until a month after that. On the other hand localized nature of fibrosis and its maturity are more in favor of lesions occurring before the traumatic incident one month back. The narrow neck, the appearance of cavity and the typical locations are more in favor of congenital diverticulae than traumatic aneurysms (3). Therefore it is prudent to diagnose the case as congenital fibrous diverticular disease of the heart. The narrow neck of fibrous lesion makes the case more specific. 


\section{References}

1. Schoen FJ, The heart .In: Kumar V, Abbas AK, Fausto. N, eds Robbins and Cotran Pathologic Basis of Disease. Philadelphia PA: Saunders;2004:564-71

2. Vazquez ï Jimenez J, Cardiac Diverticula. Orphanet Encyclopedia. January 2003. http;//www.orph.net /data/patho/GB/ukcdiverticulum pdf.

3. Srichai MB, Hecht EM, Kim DC,Jacobs JE, Ventricular Diverticula on Cardiac CT: More Common Than Previously Though. American Roentgen Ray Society. 2007;189:204-8.

4. Cooke, C T, Nolan, J R, Kilburn, C J .Sudden Death Associated with a Cardiac Diverticulum. The American Journal of Forensic Medicine and Pathology. 1991;12(4):340-3.

5. Gowitt, G T. Zaki, S A. Rupture of a Cardiac Diverticulum Resulting in Sudden Death. The American Journal of Forensic Medicine and Pathology. 1988; 9(2):155-8.

6. Nandi.PL, Turk WCG, Tse TF. Congenital calcified Left Ventricular Aneurysm with Mitral regurgitation: A Case Report. Journal of Hong Kong Medical Association. 1998;40(1) : 61-3.
7. Pretre R, Chilcott M. Blunt Trauma to heart and great vessels. Review Article, The New England Journal of Medicine. 1997;27 : 62632.

8. Hislop WS, Cardiac Rupture in post myocardial infarction syndrome, Postgraduate Medical Journal. 1978; 54:12932.

9. Richard Curran, Hugh S.Paterson, Surgical Treatment of intramyocardial foregut cysts. Annals of Thoracic surgery. 2005;80:737-9

10. Mustafa Kosecik, Mustafa Karaoglanoglu, Birol Yamak, Pericardial hydatid cyst presenting with cardiac tamponade, Canadian Journal of Cardiology.2006;22: 145-7.

11. IijiyamaY, Noda H. Suminaga YYamada S, Konishi F, A foregut cyst mimicking a cystic pancreatic tumor-report of a case. Jichi Medical journal. 2005;28 :117-22

12. Robinson CLN, Review article:Foregut cysts Canadian Medical Association Journal. 1963;88:.844-35. 